\title{
Filtration of Linear Recurrent Sequences with Random Delay and Random Initial Phase
}

\author{
M.G. Bakulin \\ Department of Theory of Electrical Circuits \\ V.B. Kreyndelin ${ }^{2}$ \\ Department of Theory of Electrical Circuits \\ D.Yu. Pankratov ${ }^{3}$ \\ Department of Systems and Networks of Radio Communications and Radio Broadcasting \\ Moscow Technical University of Communications and Informatics \\ 1m.g.bakulin@gmail.com, ${ }^{2}$ vitkr@gmail.com, ${ }^{3}$ dpankr@mail.ru
}

\begin{abstract}
Radio communication systems, especially mobile communication systems, are improving very fast towards 5G systems. As the requirements for radio communication systems increase the requirements for synchronization also increase. Linear recurrent sequences are widely used in radio communications systems and in this paper filtration algorithm for such sequences are considered. The results of computer simulation of the algorithms for various signal-to-noise ratios and accumulation time are presented. The synthesized algorithms can be classified as quasi-noncoherent (subincoherent) algorithms, as opposed to noncoherent algorithms that use averaging over the entire region of phase uncertainty, or from coherent, which use the exact phase of the received signal.
\end{abstract}

Key words: radio communication systems, filtration algorithms, Markov chains, linear recurrent sequences, synchronization algorithms, quasi-noncoherent algorithms, noncoherent algorithms, quasi-coherent algorithms, coherent algorithms.

\section{INTRODUCTION}

Pseudo-random signals based on linear recurrent sequences (LRS) [1-4] are widely used in various information systems [5]. LRS synchronization in such systems is usually performed by multichannel correlators or cyclic search schemes [6-9]. With a long sequence length and a wide area of uncertainty over the delay, the implementation of these approaches requires significant technical and time resources.

Known algorithms for receiving LRS that solve the problem of accelerated synchronization are based on the Ward method [10]. This method allows to reduce the time of search and synchronization of LRS. In Ward's method, the LRS generator is started by a sequence of previously received characters. However, this method has acceptable characteristics only at a sufficiently high signal-to-noise ratio (SNR). Decreasing the SNR significantly degrades the effectiveness of the Ward method. To improve the efficiency of the Ward method while decreasing the SNR, different modifications were proposed [11$14]$.

The known algorithms of filtration for linear recurrent sequences using the Markov properties of these LRSs allow to improve the synchronization performance [11-14]. However, these methods belong to coherent reception methods and require precise knowledge of the phase of the received radio signal. It is known [15] that coherent methods provide the highest noise immunity during LRS receiving. However, in reality the received signal always has random initial phase. Therefore, the use of coherent methods of reception requires an estimation of this phase and for obtaining the phase estimate the use of appropriate algorithms and additional time are required. This ultimately increases the total time for synchronization.

In this paper, we solve the problem of LRS filtration algorithm synthesizing for accelerated synchronization, which does not require knowledge of the phase of the received radio signal. The proposed algorithm can be used for accelerated synchronization and, as the simulation results show, remains operable even for negative SNR values.

\section{PROBLEM STATEMENT}

Let the LRS be described by the following recurrent relation: $b_{n}=\sum_{i=1}^{k} \oplus \delta_{i} b_{n-i}, \delta_{i} \in\{0 ; 1\}, b_{n} \in\{0 ; 1\}, i \in 1, \ldots, k(1)$ where $k$ is the length of LRS register; $n$ is discrete time; $\operatorname{sign} \oplus$ means modulo 2 sum.

It is known [16] that the operations of modulo 2 addition in the alphabet $\{0 ; 1\}$ correspond to the operations of modulo 2 addition in the alphabet $\{1 ;-1\}$. Based on this, from (1) we can get: 


$$
B_{n}=\prod_{i=1}^{k}\left(\left(1-\delta_{i}\right)+\delta_{i} B_{n-i}\right)
$$

where $B_{n}=1-2 b_{n}, B_{n} \in\{1 ;-1\}$

Expressions (1) and (2) describe the rule for LRS generation and are valid for any cyclic shift. Therefore, the problem of LRS synchronization, which consists in estimating the number of cyclic shift (discrete delay) of the observed sequence, can be considered as the problem of estimating the current LRS segment of length $\mathrm{k}$ characters, i.e. k-dimensional vector estimation $\mathbf{B}_{n} \square\left[\begin{array}{lll}B_{n} & \cdots & B_{n-k+1}\end{array}\right]$.

For the sake of simplicity of the further consideration, let us assume that LRS register has only one tap, i.e.:

$$
\delta_{i}=\left\{\begin{array}{l}
1, i=l \\
0, i \neq l
\end{array}, \quad i=1, \ldots k, 1<l<k\right.
$$

We assume that the pseudo-random binary sequence (PRBS) is transmitted using binary phase shift keying (BPSK). Taking into account (1)-(3) we can write the following model:

$$
\left\{\begin{array}{c}
B_{n}=B_{n-l} B_{n-k} \\
y_{c, n}=B_{n} \cos \varphi+\eta_{c, n}, \quad \eta_{c, n} \square N\left(0, \sigma_{\eta}{ }^{2}\right), \\
y_{s, n}=B_{n} \sin \varphi+\eta_{s, n}, \quad \eta_{s, n} \square N\left(0, \sigma_{\eta}{ }^{2}\right)
\end{array}\right.
$$

where $\varphi$ is random phase, but it does not change on the observation interval and uniformly distributed on the interval $[-\pi ; \pi] ; \eta_{n c}, \eta_{n s}$ are uncorrelated sequences of Gaussian random variables with zero means and variances $\sigma_{\eta}^{2} ; y_{n c}, y_{n s}$ are observed signals. The equation of state in model (4) (upper equation) is written taking into account the fact that LRS can be considered as a degenerate case of a Markov chain.

The task of synchronizing LRS is to estimate the current segment $\mathbf{B}_{n} \square\left[\begin{array}{lll}B_{n} & \cdots & B_{n-k+1}\end{array}\right]$ from the observation $\mathbf{y}_{n}=\left(y_{1}, y_{2}, \ldots y_{n}\right)$, where $y_{n} \square\left[\begin{array}{ll}y_{c, n} & y_{s, n}\end{array}\right]$.

Model (4) can be transformed and represented in the following form:

$$
\left\{\begin{array}{l}
B_{n}=B_{n-l} B_{n-k} \\
y_{c, n}=B_{n} \theta_{c}|\cos \varphi|+\eta_{c, n} \\
y_{s, n}=B_{n} \theta_{s}|\sin \varphi|+\eta_{s, n}
\end{array}\right.
$$

where $\theta_{c}=\operatorname{sign}(\cos (\varphi)) \in\{-1 ; 1\}$;

$\theta_{s}=\operatorname{sign}(\sin (\varphi)) \in\{-1 ; 1\}$ are additional symbols that take into account the position of the phase vector in the corresponding half-planes.

Let us introduce the notation for the following sequences:

$$
B_{c, n} \sqcup B_{n} \theta_{c}, B_{s, n}=B_{n} \theta_{s}
$$

It is not difficult to show that $B_{c, n}=B_{c, n-l} B_{c, n-k} \theta_{c}$, $B_{s, n}=B_{s, n-l} B_{s, n-k} \theta_{s}$.

We divide the equations of state and observation (5) into two independent systems:

$$
\left\{\begin{array}{l}
B_{c, n}=B_{c, n-l} B_{c, n-k} \theta_{c, n-1} \\
\theta_{c, n}=\theta_{c, n-1} \\
y_{c, n}=B_{c, n} \cos \varphi_{c}+\eta_{c, n}
\end{array}\right.
$$

and

$$
\left\{\begin{array}{l}
B_{s, n}=B_{s, n-l} B_{s, n-k} \theta_{s, n-1} \\
\theta_{s, n}=\theta_{s, n-1} \\
y_{s, n}=B_{s, n} \sin \varphi_{s}+\eta_{s, n}
\end{array}\right.
$$

where $\varphi_{c}$ is random phase uniformly distributed on the interval $[-\pi / 2 ; \pi / 2] ; \varphi_{s}$ is random phase uniformly distributed on the interval $[0 ; \pi]$.

Thus, the task of synchronizing LRS can be divided into the following subtasks:

1. Using the systems of equations of state and observation (7) and (8), estimate the k-dimensional segments of two independent LRSs $\mathbf{B}_{c, n}, \mathbf{B}_{s, n}$ and random binary values $\theta_{c, n}, \theta_{s, n}$.

2. Using estimates of segments $\mathbf{B}_{c, n}, \mathbf{B}_{s, n}$ and random binary values $\theta_{c, n}, \theta_{s, n}$ estimate the segment of source LRS $\mathbf{B}_{n}$.

\section{SYNTHESIS OF THE ALGORITHM}

Consider first the synthesis of synchronization algorithm of sequence $B_{n, c}$ using model (7).

Using the Bayes formula [15], we can obtain an expression for the joint a posteriori distribution of the vector $\mathbf{B}_{c, n} \square\left[B_{c, n}, B_{c, n-1}, \ldots, B_{c, n-k+1}\right]$ and parameters $\theta_{c, n}$, at the $n$-th filtration step:

$$
\begin{aligned}
& p\left(\mathbf{B}_{c, n}, \theta_{c, n} / \mathbf{y}_{c, n}\right)= \\
& =D\left(y_{c, n}\right) \cdot p\left(\mathbf{B}_{c, n}, \theta_{c, n} / \mathbf{y}_{c, n-1}\right) \cdot p\left(\mathbf{y}_{c, n} / B_{c, n}\right)
\end{aligned}
$$

This equation takes into account that the current observation $y_{c, n}$ depends only on the current LRS character $B_{c, n}$ and does not depend on the rest of the estimated characters.

The relation for the likelihood function can be written as follows: 
$p\left(\mathrm{y}_{n} / B_{c, n}\right)=\int_{-\pi / 2}^{\pi / 2} p\left(\mathrm{y}_{n} / B_{c, n}, \varphi_{c}\right) \cdot p\left(\varphi_{c}\right) d \varphi_{c}$

where $p\left(\varphi_{c}\right)=\frac{1}{\pi}$ for $-\frac{\pi}{2} \leq \varphi_{c} \leq \frac{\pi}{2}$.

From observation equation of system (7), we can write the expression for the likelihood function:

$$
\begin{gathered}
p\left(\mathrm{y}_{n} / B_{c, n}, \varphi_{c}\right)= \\
=C \exp \left(-\frac{1}{2 \sigma_{\eta}^{2}}\left(y_{c, n}-B_{c, n} \cos \left(\varphi_{c}\right)\right)^{2}\right)= \\
=\frac{1}{2} C \exp \left(-\frac{y_{c, n}^{2}}{2 \sigma_{\eta}^{2}}\right) \exp \left(-\frac{\cos \left(\varphi_{c}\right)^{2}}{2 \sigma_{\eta}^{2}}\right) \\
\cdot\left(\cosh \left(\cos \left(\varphi_{c}\right)\right)+B_{c, n} \sinh \left(\cos \left(\varphi_{c}\right)\right)\right)
\end{gathered}
$$

Substituting (11) into (10) after averaging, we get

$$
\begin{gathered}
p\left(\mathrm{y}_{n} / B_{c, n}, \varphi_{c}\right)= \\
=C \exp \left(-\frac{1}{2 \sigma_{\eta}^{2}}\left(y_{c, n}-B_{c, n} \cos \left(\varphi_{c}\right)\right)^{2}\right)= \\
=\frac{1}{2} C \exp \left(-\frac{y_{c, n}^{2}}{2 \sigma_{\eta}^{2}}\right) \exp \left(-\frac{\cos \left(\varphi_{c}\right)^{2}}{2 \sigma_{\eta}^{2}}\right) \cdot \\
\cdot\left(\cosh \left(\frac{y_{c, n}}{\sigma_{\eta}^{2}} \cos \left(\varphi_{c}\right)\right)+B_{c, n} \sinh \left(\frac{y_{c, n}}{\sigma_{\eta}^{2}} \cos \left(\varphi_{c}\right)\right)\right) \\
=\frac{1}{2} C_{2}\left(1+B_{c, n} T_{c, n}\right)
\end{gathered}
$$

where

$$
\begin{gathered}
T_{c, n} \square T_{c}\left(\frac{y_{c, n}}{\sigma_{\eta}^{2}}\right)= \\
=\frac{\int_{-\pi / 2}^{\pi / 2} \exp \left(-\frac{\cos \left(\varphi_{c}\right)^{2}}{2 \sigma_{\eta}^{2}}\right) \sinh \left(\frac{y_{c, n}}{\sigma_{\eta}^{2}} \cos \left(\varphi_{c}\right)\right) d \varphi_{c}}{\int_{-\pi / 2}^{\pi / 2} \exp \left(-\frac{\cos \left(\varphi_{c}\right)^{2}}{2 \sigma_{\eta}^{2}}\right) \cosh \left(\frac{y_{c, n}}{\sigma_{\eta}^{2}} \cos \left(\varphi_{c}\right)\right) d \varphi_{c}}
\end{gathered}
$$

Assuming a posteriori independence of the vector elements $\mathbf{B}_{c, n-1}$ between themselves and и value $\theta_{c, n-1}$ at $n$-1-th filtration step we can write:

$$
\begin{gathered}
p\left(\mathbf{B}_{c, n-1}, \theta_{c, n-1} / \mathbf{y}_{c, n-1}\right)= \\
=p\left(\theta_{c, n-1} / \mathbf{y}_{c, n-1}\right) \prod_{i=1}^{k} p\left(B_{c, n-i} / \mathbf{y}_{c, n-1}\right)
\end{gathered}
$$

Ошибка! Закладка не определена.
Since $B_{n-i}= \pm 1, \quad i=1, \ldots k \quad$ and $\quad \theta_{c, n-1}= \pm 1 \quad$ are random binary values, the corresponding a posteriori probabilities are described by the following expressions [16]:

$$
\begin{gathered}
p\left(\theta_{c, n-1} / \mathbf{y}_{c, n-1}\right)=\frac{1}{2}\left(1+\hat{\theta}_{c, n-1} \theta_{c, n-1}\right) \\
p\left(B_{c, n-i} / \mathbf{y}_{c, n-1}\right)= \\
=\frac{1}{2}\left(1+\hat{B}_{c, n-i}^{(n-1)} B_{c, n-i}\right), i=1, \ldots k
\end{gathered}
$$

where $\hat{\theta}_{c, n-1}=E\left\{\theta_{c, n-1} / \mathbf{y}_{c, n-1}\right\}$, $\hat{B}_{c, n-i}^{(n-1)}=E\left\{B_{c, n-i} / \mathbf{y}_{c, n-1}\right\}$ estimates of $\theta_{c, n-1}$ and $B_{c, n-i}$, $i=1, \ldots k$ values on $n$-1-th filtration step, optimal by the criterion of the minimum mean square error.

Taking into account the equation of state in expression (7) and expressions (14), we can write:

$$
\begin{gathered}
p\left(\mathbf{B}_{c, n}, \theta_{c, n} / \mathbf{y}_{c, n-1}\right)=\frac{1}{2}\left(1+\hat{\theta}_{c, n-1} \theta_{c, n}\right) . \\
\cdot \frac{1}{2}\left(\left(1+\hat{B}_{c, n-k}^{(n-1)} B_{c, n-l} B_{c, n} \theta_{c, n}\right)\right) . \\
\cdot \prod_{i=1}^{k-1} \frac{1}{2}\left(1+\hat{B}_{c, n-i}^{(n-1)} B_{c, n-i}\right)
\end{gathered}
$$

Substituting (15) and (12) into (9) and transforming, we obtain a recurrent algorithm for calculating estimates:

$$
\begin{aligned}
& \hat{B}_{c, n-r}^{(n)}=\left\{\begin{array}{l}
\hat{B}_{c, n-r}^{(n-1)}, \quad r \neq l, r \neq 0 \\
\hat{B}_{c, n-l}^{(n-1)}+T_{c, n} \hat{\theta}_{c, n-1} \hat{B}_{c, n-k}^{(n-1)} \\
1+T_{c, n} \hat{\theta}_{c, n-1} \hat{B}_{c, n-l}^{(n-1)} \hat{B}_{c, n-k}^{(n-1)} \\
\frac{T_{c, n}+\hat{\theta}_{c, n-1} \hat{B}_{c, n-l}^{(n-1)} \hat{B}_{c, n-k}^{(n-1)}}{1+T_{c, n} \hat{\theta}_{c, n-1} \hat{B}_{c, n-l}^{(n-1)} \hat{B}_{c, n-k}^{(n-1)}}, r=0
\end{array}\right. \\
& \hat{\theta}_{c, n}=\frac{\hat{\theta}_{c, n-1}+T_{c, n} \hat{B}_{c, n-l}^{(n-1)} \hat{B}_{c, n-k}^{(n-1)}}{1+T_{c, n} \hat{\theta}_{c, n-1} \hat{B}_{c, n-l}^{(n-1)} \hat{B}_{c, n-k}^{(n-1)}}
\end{aligned}
$$

Using the well-known relation for hyperbolic functions, the resulting algorithm can be transformed to a somewhat simpler form: 


$$
\begin{aligned}
& \hat{B}_{c, n-r}^{(n)}=\left\{\begin{array}{l}
\hat{B}_{c, n-r}^{(n-1)}, \quad r \neq l, r \neq 0 \\
\tanh \left(\operatorname{atanh}\left(\hat{B}_{c, n-l}^{(n-1)}\right)+\right. \\
\left.+\operatorname{atanh}\left(T_{c, n} \hat{\theta}_{c, n-1} \hat{B}_{c, n-k}^{(n-1)}\right)\right), \quad r=l, r=0, \ldots k-1 \\
\tanh \left(\operatorname{atanh}\left(T_{c, n}\right)+\right. \\
\left.+\operatorname{atanh}\left(\hat{\theta}_{c, n-1} \hat{B}_{c, n-l}^{(n-1)} \hat{B}_{c, n-k}^{(n-1)}\right)\right), \quad r=0
\end{array}\right. \\
& \hat{\theta}_{c, n}=\tanh \left(\operatorname{atanh}\left(\hat{\theta}_{c, n-1}\right)+\operatorname{atanh}\left(T_{c, n} \hat{B}_{c, n-l}^{(n-1)} \hat{B}_{c, n-k}^{(n-1)}\right)\right)
\end{aligned}
$$

Introducing the notation $\hat{\beta}_{c, n-r}^{(n)} \square \operatorname{atanh}\left(\hat{B}_{c, n-r}^{(n)}\right)$, $\hat{\vartheta}_{c, n} \sqcap \operatorname{atanh}\left(\hat{\theta}_{c, n}\right), \quad \tau_{c, n}=\operatorname{atanh}\left(T_{c, n}\right) \quad$ we get the following algorithm:

$\hat{\beta}_{c, n-r}^{(n)}=\left\{\begin{array}{l}\hat{\beta}_{c, n-r}^{(n-1)}, r \neq l, r \neq 0 \\ \hat{\beta}_{c, n-r}^{(n)}+\operatorname{atanh}\left(\tanh \left(\tau_{c, n}\right) .\right. \\ \left.\cdot \tanh \left(\hat{\vartheta}_{c, n-1}\right) \tanh \left(\hat{\beta}_{c, n-k}^{(n-1)}\right)\right), r=l, r=0, \ldots k-1 \\ \tau_{c, n}+\operatorname{atanh}\left(\tanh \left(\hat{\vartheta}_{c, n-1}\right) .\right. \\ \left.\cdot \tanh \left(\hat{\beta}_{c, n-l}^{(n-1)}\right) \tanh \left(\hat{\beta}_{c, n-k}^{(n-1)}\right)\right), \quad r=0\end{array}\right.$

$$
\hat{\vartheta}_{c, n}=\hat{\vartheta}_{c, n-1}+\operatorname{atanh}\left(\tanh \left(\tau_{c, n}\right) \tanh \left(\hat{\beta}_{c, n-l}^{(n-1)}\right) \tanh \left(\hat{\beta}_{c, n-k}^{(n-1)}\right)\right)
$$

A further simplification of the algorithm is based on the following approximation [10]:

$$
\begin{gathered}
\operatorname{atanh}\left(\prod_{i} \tanh \left(x_{i}\right)\right) \approx \\
\approx \min _{i}\left(\left|x_{i}\right|\right) \prod_{i} \operatorname{sign}\left(x_{i}\right) \square F\left(x_{1}, x_{2}, \ldots\right)
\end{gathered}
$$

Finally, we get

$$
\begin{aligned}
& \hat{\beta}_{c, n-r}^{(n)}=\left\{\begin{array}{l}
\hat{\beta}_{c, n-r}^{(n-1)}, r \neq l, r \neq 0 \\
\hat{\beta}_{c, n-r}^{(n)}+ \\
+F\left(\tau_{c, n}, \hat{\vartheta}_{c, n-1}, \hat{\beta}_{c, n-k}^{(n-1)}\right), r=l, r=0, \ldots k-1 \\
\tau_{c, n}+F\left(\hat{\vartheta}_{c, n-1}, \hat{\beta}_{c, n-l}^{(n-1)}, \hat{\beta}_{c, n-k}^{(n-1)}\right), r=0
\end{array}\right. \\
& \hat{\vartheta}_{c, n}=\hat{\vartheta}_{c, n-1}+F\left(\tau_{c, n}, \hat{\beta}_{c, n-l}^{(n-1)}, \hat{\beta}_{c, n-k}^{(n-1)}\right)
\end{aligned}
$$

As an approximation, you can use the following algorithm:

$$
\begin{aligned}
& \hat{\beta}_{c, n-r}^{(n)}=\left\{\begin{array}{l}
\hat{\beta}_{c, n-r}^{(n-1)}, r \neq l, r \neq 0 \\
\hat{\beta}_{c, n-r}^{(n)}+ \\
+F\left(y_{c, n}, \hat{\vartheta}_{c, n-1}, \hat{\beta}_{c, n-k}^{(n-1)}\right), r=l, r=0, \ldots k-1 \\
y_{c, n}+F\left(\hat{\vartheta}_{c, n-1}, \hat{\beta}_{c, n-l}^{(n-1)}, \hat{\beta}_{c, n-k}^{(n-1)}\right), r=0
\end{array}\right. \\
& \hat{\vartheta}_{c, n}=\hat{\vartheta}_{c, n-1}+F\left(y_{c, n}, \hat{\beta}_{c, n-l}^{(n-1)}, \hat{\beta}_{c, n-k}^{(n-1)}\right)
\end{aligned}
$$

This approximation is based on the relation, that $\tau_{c, n} \square y_{c, n}$

Similarly, an estimation algorithm of $\mathbf{B}_{s, n}$ and $\theta_{s, n}$ for model (8) can be obtained. Omitting the intermediate transformations, we can write

$$
\begin{aligned}
& \hat{\beta}_{s, n-r}^{(n)}=\left\{\begin{array}{l}
\hat{\beta}_{s, n-r}^{(n-1)}, r \neq l, r \neq 0 \\
\hat{\beta}_{s, n-r}^{(n)}+ \\
+F\left(y_{s, n}, \hat{\vartheta}_{s, n-1}, \hat{\beta}_{s, n-k}^{(n-1)}\right), r=l, r=0, \ldots k-1 \\
y_{s, n}+F\left(\hat{\vartheta}_{s, n-1}, \hat{\beta}_{s, n-l}^{(n-1)}, \hat{\beta}_{s, n-k}^{(n-1)}\right), r=0
\end{array}\right. \\
& \hat{\vartheta}_{s, n}=\hat{\vartheta}_{s, n-1}+F\left(y_{s, n}, \hat{\beta}_{s, n-l}^{(n-1)}, \hat{\beta}_{s, n-k}^{(n-1)}\right)
\end{aligned}
$$

where the following notation and definitions of the variables are used: $\hat{\beta}_{s, n-r}^{(n)} \sqcap \operatorname{atanh}\left(\hat{B}_{s, n-r}^{(n)}\right), \hat{\vartheta}_{s, n} \square \operatorname{atanh}\left(\hat{\theta}_{s, n}\right)$

The following initial conditions are used in the recurrent algorithms (20) and (22):

$$
\begin{aligned}
& \hat{\beta}_{c,-r}=\hat{\beta}_{s,-r}=0, r=1, \ldots, k \\
& \hat{\vartheta}_{c, 0}=\hat{\vartheta}_{s, 0}=0
\end{aligned}
$$

It should be noted that the synthesized algorithms estimate the received sequences for each quadrature component up to the sign. In this case, each of them uses averaging over the initial phase in the range of uncertainty with a width of $\pi$, i.e. equal to half the width of the general uncertainty range $2 \pi$. Therefore, these algorithms can be classified as quasi-noncoherent (subincoherent) algorithms, as opposed to noncoherent algorithms that use averaging over the entire region of phase uncertainty, or from coherent and quasi-coherent, which use the exact phase or its estimation, respectively.

The second stage of LRS synchronization is to obtain an estimate of the segment of the initial sequence using the results obtained at the first stage. Consider the following approach. As a result of the work of the algorithms (20) and (22), we have the following a posteriori distributions

$$
\begin{aligned}
& p_{p s}\left(B_{c, n}\right)=\frac{1}{2}\left(1+B_{c, n} \hat{B}_{c, n}^{(n)}\right) \\
& p_{p s}\left(B_{s, n}\right)=\frac{1}{2}\left(1+B_{s, n} \hat{B}_{s, n}^{(n)}\right)
\end{aligned}
$$

From these a posteriori distributions, equivalent likelihood functions can be obtained: 


$$
\begin{aligned}
& \Lambda\left(B_{c, n}\right)=C \frac{p_{p s}\left(B_{c, n}\right)}{p_{p r}\left(B_{c, n}\right)}=C\left(1+B_{c, n} \hat{B}_{c, n}^{(n)}\right) \\
& \Lambda\left(B_{s, n}\right)=C \frac{p_{p s}\left(B_{s, n}\right)}{p_{p r}\left(B_{s, n}\right)}=C\left(1+B_{s, n} \hat{B}_{s, n}^{(n)}\right)
\end{aligned}
$$

where the distribution of equiprobable binary symbols was used as a priori distribution of random binary values $B_{c . n}, B_{s, n}$ :

$$
p_{p r}\left(B_{c, n}\right)=p_{p r}\left(B_{s, n}\right)=\frac{1}{2}
$$

Given the definition of sequences $B_{c . n}, B_{s, n}$ in (6) and equivalent likelihood functions (25), we can write the following state and observation model:

$$
\left\{\begin{array}{l}
B_{n}=B_{n-l} B_{n-k} \\
\hat{B}_{c, n}=B_{n} \theta_{c, n} \\
\hat{B}_{s, n}=B_{n} \theta_{s, n}
\end{array}\right.
$$

As a priori distribution for random binary values, the following a posteriori distributions can be used:

$$
\begin{aligned}
& p_{p s}\left(\theta_{c, n}\right)=\frac{1}{2}\left(1+\theta_{c, n} \hat{\theta}_{c, n-1}^{(n-1)}\right) \\
& p_{p s}\left(\theta_{s, n}\right)=\frac{1}{2}\left(1+\theta_{s, n} \hat{\theta}_{s, n-1}^{(n-1)}\right)
\end{aligned}
$$

After the transformation, we get

$$
\begin{aligned}
& \hat{\beta}_{n-r}^{(n)}=\left\{\begin{array}{l}
\hat{\beta}_{n-r}^{(n-1)}, r \neq l, r \neq 0 \\
\hat{\beta}_{n-l}^{(n-1)}+F\left(Z_{n}, \hat{\beta}_{n-k}^{(n-1)}\right), r=l, \quad r=0,1, \ldots k-1 \\
F\left(\hat{\beta}_{n-l}^{(n-1)}, \hat{\beta}_{n-k}^{(n-1)}\right)+Z_{n}, r=0
\end{array}\right. \\
& Z_{n}=F\left(\hat{\vartheta}_{s, n-1}, \hat{\beta}_{s, n}^{(n)}\right)+F\left(\hat{\vartheta}_{c, n-1}, \hat{\beta}_{c, n}^{(n)}\right)
\end{aligned}
$$

The initial conditions for the algorithm (28) are as follows:

$$
\hat{\beta}_{-r}=0, r=1, \ldots, k
$$

Fig. 1 shows a block diagram of the synthesized filtration algorithm of LRS with a random delay and a random initial phase (algorithms (21), (22), (28)). It contains two identical channels for processing quadrature components (algorithms (21) and (22)) that implement the first processing stage, the blocks combining the processing results of the first stage, and the LRS filtration block that implements the second stage of LRS filtration. It should be noted that the blocks marked with a dashed line in this scheme implement a coherent filtration algorithm of LRS, which coincides with the algorithm described in [12]. The structure of the signal processing unit of the inphase quadrature component of the first stage is shown in Fig. 2. In this scheme, the dashed line circled the blocks, estimating the sign of the phase multiplier of the quadrature component $\vartheta_{c}$.
The processing unit of another quadrature component has an identical block diagram.

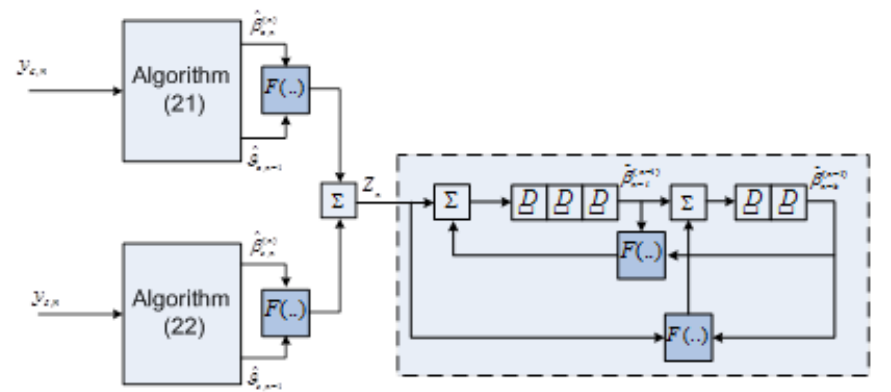

Fig. 1. Block diagram of the filtration algorithm of LRS with random delay and random initial phase

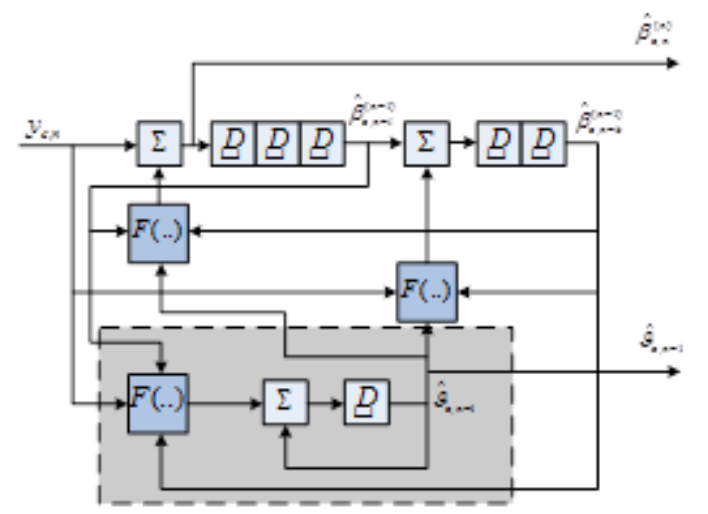

Fig. 2. Block diagram of a processing algorithm of one quadrature component (21)

Thus, the synthesized filtration algorithm of LRS with random delay and random initial phase is a two-stage combination of a coherent algorithm and algorithms for individual filtration of signals of quadrature components, which are LRS filtration algorithms with sign inversion. According to its classification, it refers to quasi-noncoherent algorithms.

\section{SIMULATION AND ANALYSIS OF RESULTS}

The characteristics of the developed algorithms were investigated by statistical simulation. During the simulation, LRS with a period of $M=2^{11}-1$ (characteristic polynomial (100000000101) was used.

Figure 3 shows the dependence of correct estimation probability (Prob) of the current state of the forming shift register on the accumulation time $(\mathrm{N})$ for the synthesized algorithm (21)-(23), (26) ('subincoherent'). The same figure shows the characteristics of the filtration algorithm of LRS with a known phase (the coherent algorithm - 'coherent'), described in $[11 ; 12]$. Figure 4 shows the dependence of correct estimation probability (Prob) of the current state of the forming shift register on the signal-to-noise ratio (SNR) for the same algorithms.

It can be seen from the above figures that with a sample length of 600 characters of the LRS and a signal-to-noise ratio of $8 \mathrm{~dB}$, the characteristics of the proposed quasi-noncoherent algorithm practically coincide with the characteristics of the coherent algorithm. With a larger sample length, the proposed structure of the algorithm provides a greater probability of correct synchronization than a coherent algorithm. This is explained by the fact that in the proposed algorithm, in addition to evaluating the signs of the quadrature components in the first stage, the second stage of LRS filtration is used that finally leads to improved filtration quality. 


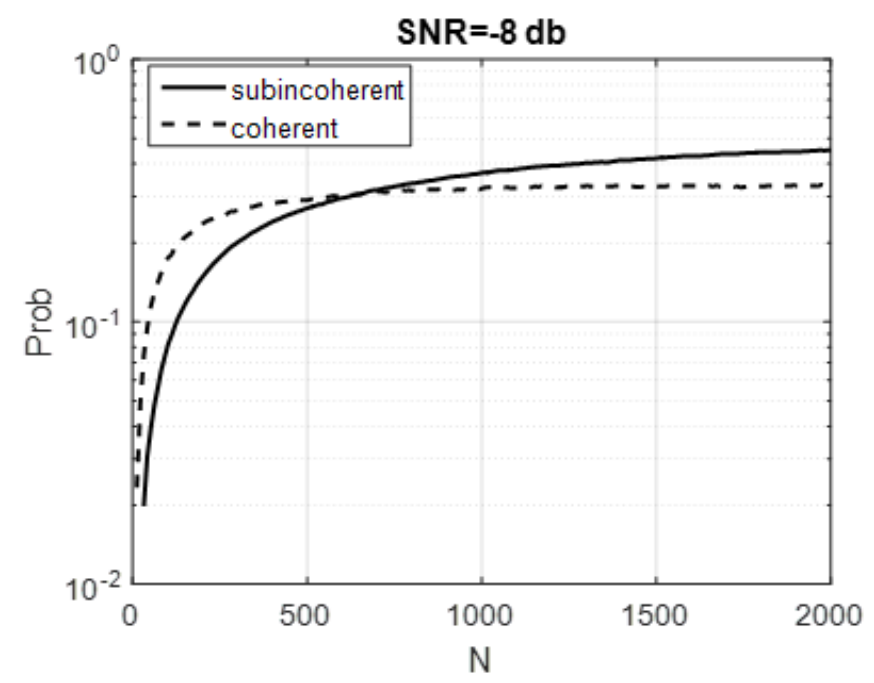

Fig. 3. Dependences of correct estimation probability (Prob) of the current state of the forming shift register on the accumulation time $(\mathrm{N})$ for the synthesized algorithm (21)-(23), (26) ('subincoherent') and coherent algorithm from [11] ('coherent')

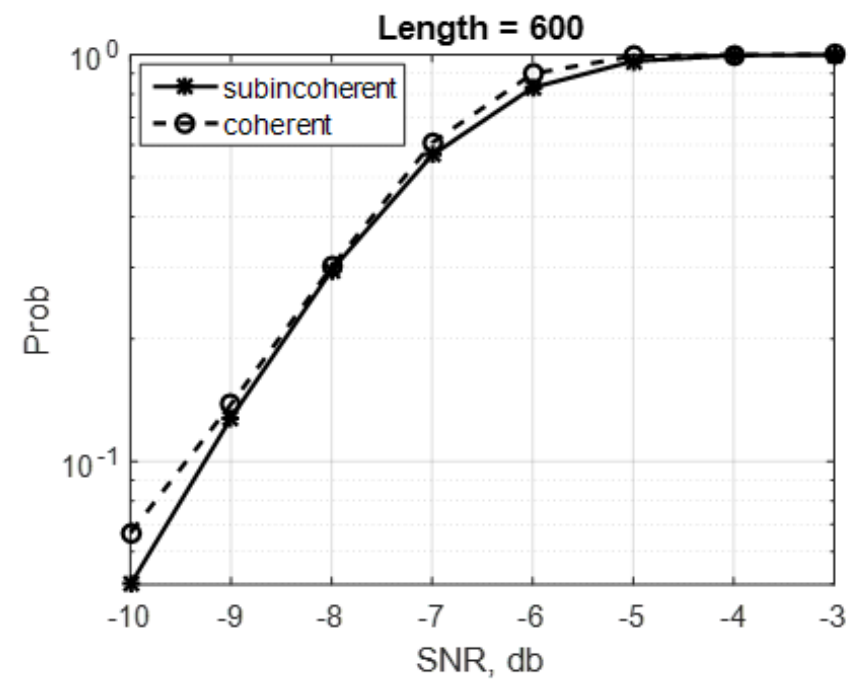

Figure 4. Dependences of correct estimation probability (Prob) of the current state of the forming shift register on the signal-to-noise ratio (SNR) of the synthesized algorithm (21)-(23), (26) ('subincoherent') and coherent from [11]

Thus, LRS filtration algorithms (21)-(23), (28)-(29) synthesized in this work, synchronize over any segment of LRS at a random signal phase, so they can be used, in particular, in communication systems using signal ensemble based on LRS segments $[2 ; 6]$.

\section{REFERENCES}

[1] Теория и применение псевдослучайных сигналов / А.И. Алексеев, А. Г. Шереметев, Г.И, Тузов и др. М.: Наука, 1969. [Theory and Application of Pseudorandom Signals / A.I. Alekseev, A.G. Sheremetiev, G.I. Tuzov et al. Moscow: Nauka, 1969].

[2] Варакин Л.Е, Системы связи с шумоподобными сигналами. М.: Радио и связь, 1985. [Varakin L.E. Communication Systems with Pseudonoise Signals. Moscow: Radio and communication, 1985].

[3] Диксон Р.К. Широкополосные системы / Пер. В.И. Журавлев. М.: Связь, 1979., [Dickson R.K. Broadband Systems / Transl. from English, ed. by V.I. Zhuravlev. Moscow: Communication, 1979].

[4] Ипатов В. Широкополосные системы и кодовое разделение сигналов. М.: Техносфера, 2007. [Ipatov V. Broadband Systems and Code Division of Signals. Moscow: Tekhnosfera, 2007].
[5] Тепляков И.М., Рощин Б.В., Фомин А.И. Радиосистемы передачи информации. М.: Радио и связь, 1982. [Teplyakov I.M., Roshchin B.V., Fomin A.I. et al Radio Information Systems. Moscow: Radio and communication, 1982].

[6] Журавлев В.И. Поиск и синхронизация в широкополосных системах. М.: Радио и связь, 1986. [Zhuravlev V.I. Search and Synchronization in Broadband Systems. Moscow: Radio and communication, 1986].

[7] Петров Е.П., Алешкин Е.А. Метод подавления подобных помех с неизвестной амплитудой и задержкой сигнала в системах связи с шумоподобными сигналами // T-Comm: Телекоммуникации и транспорт. 2016. Т. 10, N 11. С. 34-39. [Petrov E.P., Aleshkin E.A. Method of suppression of signal-similar interference with unknown amplitude and time delay in communication systems with noise-shaped signals // T-Comm: Telecommunications and Transportation. 2016. Vol. 10. N 11. P. 34-39].

[8] Борисов В.И., Шестопалов В.И., Лимарев А.Е. и др. Оценка эффективности синхронизации по задержке в широкополосных системах связи с множественным доступом // Радиотехника. 2012. № 8. C. 4-16. [Borisov V.I., Shestopalov V.I., Limarev A.E. et al. Estimation of the effectiveness of synchronization by delay in broadband communication systems with multiple access // Radiotekhnika. 2012, N 8. P. 4-16].

[9] Шахтарин Б.И., Сизых В.В., Сидоркина Ю.А. и др. Синхронизация в радиосвязи и навигации. М.: Горячая линия — Телеком, 2011. [Shakhtarin B.I., Sizykh V.V., Sidorkina Yu.A. et al. Synchronization in Radio Communication and Radio Navigation. Moscow: Hotline-Telecom, 2011].

[10] Ward R. Acquisition of Pseudonoise Signals by Sequential Estimation // IEEE Transactions on Communications. 1965. Vol. 13, N 4. P. 475-483.

[11] Бакулин М.Г., Крейнделин В.Б. Метод приема псевдослучайных сигналов с неизвестной задержкой // Известия высших учебных заведений. Радиоэлектроника. 1991. T. 34, №4. C. 47-51. [Bakulin M.G., Kreyndelin V.B. The method of receiving pseudo-random signals with an unknown delay // News of higher educational institutions. Radio Electronics. 1991. Vol. 34, N 4. P. 47-51].

[12] Бакулин М.Г., Крейнделин В.Б., Терехов А.Л. Спектральный алгоритм фильтрации линейных реккурентных последовательностей // Радиотехника. 1994. №6. С. 66-74. [Bakulin M.G., Kreyndelin V.B., Terekhov A.L., A filtration algorithm for linear recurrent sequences from a mixture with noise // Radiotekhnika. 1994. N 6. P. 66-74].

[13] Петров Е.П., Частиков А.В., Харина Н.Л. и др Алгоритм и структура устройства быстрого поиска шумоподобных сигналов // Т-Comm: Телекоммуникации и транспорт. 2013. №4, C. 38-41. [Petrov E.P., Chastikov A.V., Kharina N.L. et al. The algorithm and the structure of the device to quickly search for noiselike signals // T-Comm: Telecommunications and Transport. 2013. N 4. P.. 38-41].

[14] Прозоров Д.Е. Метод последовательной оценки псевдослучайных сигналов на основе модели многосвязной цепи Маркова // Журнал радиоэлектроники: электронный журнал. 2013. №10 [Prozorov D.E. Method of sequential estimation of pseudo-random signals based on the model of a multiply connected Markov chain // Journal of Radio Electronics: Electronic Journal. 2013. N 10].

[15] Тихонов В.И. Оптимальный прием сигналов. М.: Радио и связь, 1983. [Tikhonov V.I. Optimal Reception of Signals. Moscow: Radio and communication, 1983].

[16] Бакулин М.Г. Фильтрация цифровых последовательностей с использованием моментного описания распределения вероятностей // Электросвязь. 2000. № 1. С. 24-27. [Bakulin M.G. Filtration of digital sequences using a moment description of the probability distribution // Electrical Communications. 2000. N 1. P. 24-27] 